\title{
Management of Cholecystectomy in a Patient with Severe Von Willebrand Disease
}

\author{
Hanaa Bencharef ${ }^{1,3^{*}}$, Abdelaziz Fadi2,3, Latifa Loukhmasse ${ }^{4}$ and Bouchra Oukkache ${ }^{1,3}$ \\ ${ }^{1}$ Hematology Laboratory, IBN ROCHD University Hospital Center, Casablanca, Morocco \\ ${ }^{2}$ Visceral Surgery Department, IBN ROCHD University Hospital Center, Casablanca, Morocco \\ ${ }^{3}$ Hassan II University, Faculty of Medicine and Pharmacy of Casablanca, Morocco \\ ${ }^{4}$ Hematology Department, Cheikh Khalifa Hospital, Casablanca, Morocco
}

\begin{abstract}
Von Willebrand disease is the most common hereditary bleeding disorder; its Type 3 is the most severe form with a high risk for surgical bleeding, both intraoperatively and during the postoperative period. Despite that, there is a scarcity of data describing the management of these patients undergoing surgical procedures. We report on a 55-years-old woman with a long history of Von Willebrand disease type 3, who had an emergency laparoscopic cholecystectomy performed using VWF/FVIII concentrate (Wilate ${ }^{\circledR}$ ), according to an adapted individual protocol, without significant bleeding or other complications. To our knowledge, this is the first case reported of a surgical procedure, under VWF/FVIII concentrate Wilate $^{\circledR}$, performed in a patient with VWD type 3 in Morocco.
\end{abstract}

\section{Keywords}

Von willebrand disease type 3, Von willebrand factor, factor VIII, VWF/FVIII concentrate Wilate ${ }^{\circledR}$, Surgical bleeding

\section{Introduction}

Von Willebrand disease (VWD) is the most common hereditary bleeding disorder with a prevalence of approximately $1 \%-2 \%$, affecting both genders equally [1]. It is a heterogeneous disease [2]; its Type 3 is defined by a total quantitative deficit in VWF. It is the most severe form of this disease, represents $5 \%$ of the forms of VWD [3] and is characterized by a low level of Von Willebrand Factor (VWF) and Factor VIII of coagulation (FVIII). The patients with VWD type 3 are at high risk for surgical bleeding, both intraoperatively and during the postoperative period. Despite that, there is a scarcity of data describing the management of patients with VWD type 3 undergoing surgical procedures. The treatment recommended in such situations is prophylactic admission of VWF/FVIII concentrate to replace the dysfunctional factors $[4,5]$. Recently, a new generation of VWF andFVIII has been developed specifically for the treatment of VWD (Wilate ${ }^{\circledR}$ ) $[6,7]$. The concentrate has been on the German market since 2005 andgained approval in other European countries and more recently Afri$\mathrm{ca}$, specifically in Morocco. The purpose of this paper is to report the case of a severe VWD type 3 who underwent cholecystectomy with the use of VWF/FVIII concentrate (Wilate ${ }^{\circledR}$ ) and to evaluate safety and efficacy of these protocols for the prevention of excessive bleedingsduring surgery.

\section{Case Report}

A 55-year-old woman presented to the emergency de- partment for a sudden onset pain in the right hypochondrium, radiating to the right shoulder, associated with nausea and vomiting. Her past medical history was remarkable with a long-standing of repeated epistaxis and menorrhagia, which were neglected by the patient. Until the age of 36 years old, the patient had presented a significant hemorrhagic syndrome following tooth extraction. This motivated a hematology consultation and the diagnosis of Willebrand disease type 3 was retained. From this age, the patient led a normal life under a follow up byhematology consultations in our institution. The physical examination located pain that blocked deep inspiration (positive murphy's sign) and a localized defense in the right hypochondrium. An abdominal ultrasound was performed showing an enlargement of the vesicular wall with a vesicular lithiasis that was $1.2 \mathrm{~cm}$ long.

*Corresponding author: Hanaa Bencharef, Hematology Laboratory, IBN ROCHD University Hospital Center, Casablanca, Morocco; Hassan II University, Faculty of Medicine and Pharmacy of Casablanca, Morocco

Accepted: September 26, 2020

Published online: September 28, 2020

Citation: Bencharef H, Fadil A, Loukhmasse L, et al. (2020) Management of Cholecystectomy in a Patient with Severe Von Willebrand Disease. Clin Hematol Res 3(1):34-37 
The results of coagulation tests are listed in (Table 1). They showed correct values of prothrombin time and fibrinogen. In addition, the platelet count was within normal range, but serum FVIII activity (FVIII: C) was abnormal, reduced to a $9 \%$ (normal range: 70-140). Von Willebrand factor antigenemia (vWF-Ag) and activity (vWF-Rco) were undetectable (normal range: 50-150\%) with incalculable VWF: Rco/VWF: Ag report. The diagnosis of acute lithiasis cholecystitis was accepted. Given the persistence and the accentuation of the pain despite an analgesic treatment by intravenous route, an emergency laparoscopic cholecystectomy was indicated. Indeed, the surgical treatment is the curative treatment of the acute lithiasis cholecystitis, since it allows the management, simultaneously, of the cause (lithiasis) and the consequence (infection). Forour patient, the risk of surgical bleeding is higher, both intraoperatively and during the postoperative period. It was believed that surgery could be performed safely if adequate levels of factor VIII could be maintained.

The patient received VWF/ FVIII concentrate (Wilate ${ }^{\circledR}$; Octapharma AG, Lachen, Switzerland) according to an adapted individual protocol developed on the basis of a multidisciplinary consultation between the hematologist, the surgeon and the anesthetist-resuscitator, while being based on the recommendations published by the High Authority for Health [8].

The loading dose was $60 \mathrm{IU} / \mathrm{kg}$ or $4500 \mathrm{IU}$ (for a weight of $70 \mathrm{~kg}$ ) twice a day as a bolus, intravenously for two days. The maintenance dose was set at half the loading dose: 30
IU/Kg or $2000 \mathrm{IU}$ once a day for 10 days. The objective was to maintain adequately a VWF and plasma FVIII level above a threshold of $50 \%$ for at least 10 days. For lack of material resources, the patient only took 5 days of the maintenance treatment instead of therecommended 10 days (Figure 1). The hemostasis assessment, carried out after 48 hours of the loading dose, which is also the same day of surgery, showed a prothrombin time at 108\%, Partial Thromboplastin Time Activated at 29 sec, the FVIII at $60 \%$, vWF-Ag $66 \%$ and vWF-Rco at $24 \%$. She recovered without any hemorrhagic incident, which is the reason tranexamic acid was not used. The patient was discharged from the hospital on the fifth days after the surgery. Considering the characteristics of her disease, we decided not to place the patient on anticoagulation therapy. Until

Table 1: Results of coagulation tests in Patient, on admission, as compared with normal values.

\begin{tabular}{|l|l|l|}
\hline Coagulation tests & Patient values & Normal values \\
\hline Clotting time (Sec) & 11 & $10-13$ \\
\hline Prothrombin time (\%) & 140 & $70-140$ \\
\hline $\begin{array}{l}\text { Partial ThromboplastinTime } \\
\text { Activated (Sec) }\end{array}$ & 48.9 & $23-33$ \\
\hline Fibrinogen (g/l) & 2,75 & $2-4$ \\
\hline Facteur VIII activity (\%) & 9 & $70-140$ \\
\hline vWF: Ag (\%) & Undetectable & $50-150$ \\
\hline vWF: Rco (\%) & Undetectable & $50-150$ \\
\hline
\end{tabular}

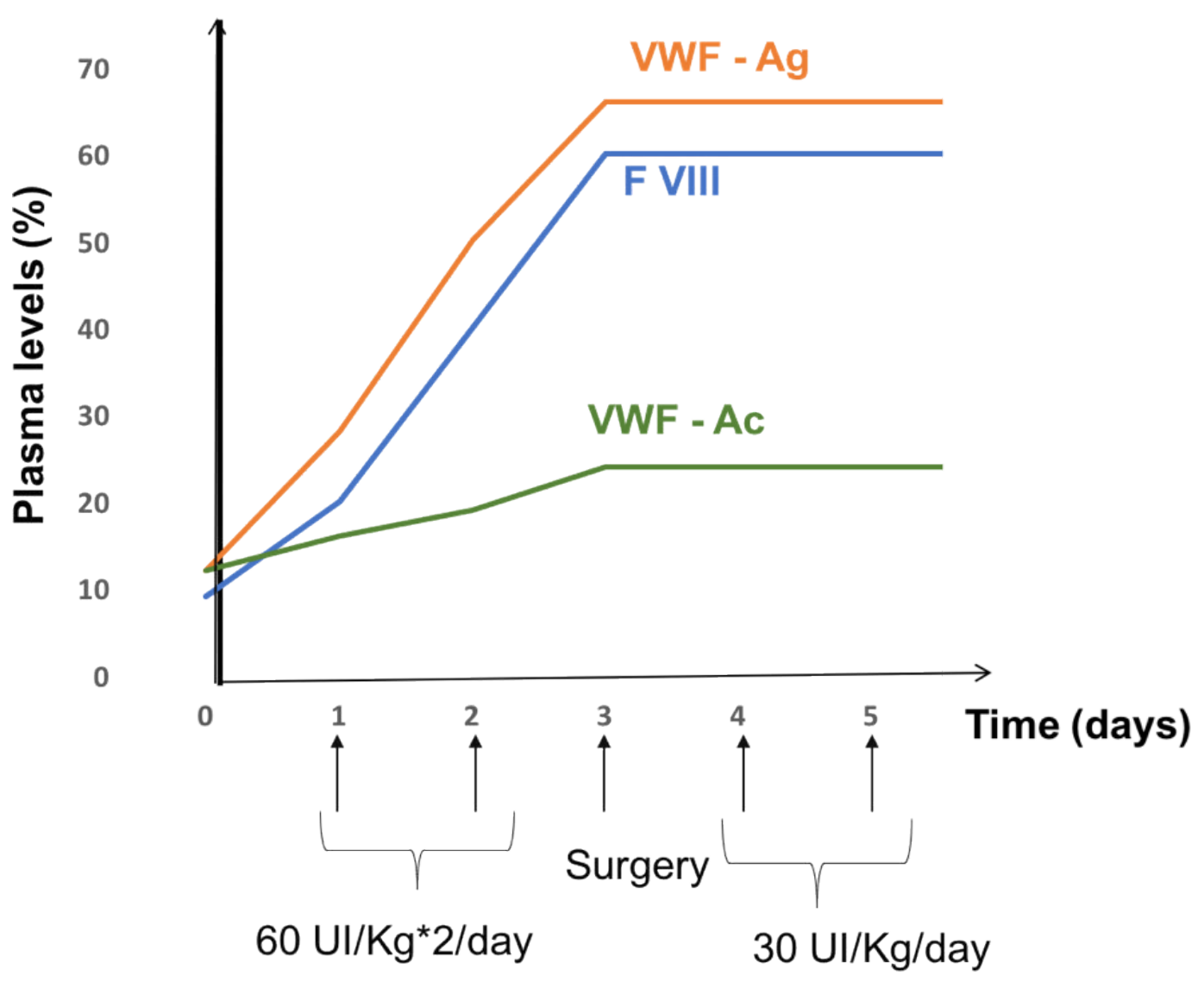

Figure 1: Representativerecovery profile in our patient receiving multiple doses of wilate ${ }^{\circledR}$. 
now, the patient is always followed in consultations without showing hemorrhagic complications in connection to the surgical operation carried out.

\section{Discussion}

Von Willebrand disease is the most common bleedingdisorder, but it is still unclear how to treat patients who undergo surgery to prevent or control the bleeding [4] since the risk of bleedingdiffers from one patient to another. Its evaluation is based on the patient's own hemorrhagic risk, his comorbidities, the treatments that can modify hemostasis, and on the hemorrhagic risk of the procedure envisaged (surgical approach, infectious context ...). This evaluation is the subject of a multidisciplinary consultation between the hematologist, the surgeon who will perform the surgery and the anesthesiologist-resuscitator, in order to write an appropriate individual therapeutic protocol.

Several countries have published recommendations: the United Kingdom $[9,10]$, the United States 11] , Italy [12] and the Netherlands [13]. All the recommendations that were made are based on observational studies or on a series of case studies. No randomized study and / or meta-analysis is available specifically concerning VWD. In addition, the classification of invasive procedures as "invasive procedure with low hemorrhagic risk" or "invasive procedure with high hemorrhagic risk" is debated in the literature. However, in general, we distinguish three maingroups: Major (operations considered dangerous orlife threatening such as orthopedic, urological, urogynecology, and abdominal surgeries); minor (invasiveprocedures not considered life threatening, such as radioactivesynovectomy and endoscopy); and dental procedures $[4,6]$.

The use of factor concentrate is recommended for type 3. However, the important consideration in the use of this factor is the ratio of vWF: Ricof / FVIII: C in the concentrate, which differsin different commercial preparations. In this case, Wilate ${ }^{\circledR}$ (Octapharma AG, Lachen, Switzerland) was used exclusively in a patient howpresents a VWD type 3 and underwent a laparoscopic cholecystectomy, which considered as a surgery at major risk of hemorrhage. It is a plasma-derived, albumin free, high purity concentrate of freeze-dried VWF and FVIII developed specifically for the treatment of VWD [7]. The manufacturing process preserves the integrity of the VWF triplet structure, and it contains two independent virus inactivation/removal steps with different modes of action. The VWF: Rco / FVIII: C ratio is close to the physiological value of $1: 1$, which should facilitate dosing and monitoring without any risk of accumulation of FVIII during repeated administrations. The concentrate has been on the German market since 2005 andgained approval in other European countries, as wellas Russia, Canada and Australia [14].

In some studies, maintenance of FVIII: C plasma levelhas been considered to be the most important while controllinghemostasis $[4,15]$. However, Nichols, et al. [11] havesuggested that vWF: Rcof is more relevant. In this case, the dose of factor was calculated according to the patient's weight, based on the recommendations published by the High Authority for Health.The objective was to maintain adequately a VWF and plasma FVIII level above a threshold of $50 \%$ for at least 10 days. But due to lack of material resources, the patient received only 5 days of maintenance treatment. She recovered without any bleeding incident and was discharged from the hospital on the fifth days after surgery.

Factor replacement can be administered via continuousinfusion or intravenous bolus infusion [16]. In this case, intravenous bolus infusion was the route of administration throughout the perioperative period. The first and largest study obtained from four European prospective, open-label, non-controlled, non-randomized, multicenter phase II or phase III clinical trials, carried out by Windyga, et al. [6], evaluated the safety and efficacy of Wilate ${ }^{\circledR}$ in the management of perioperative hemostasis in Von Willebrand disease patients undergoing surgery. A total of 57 surgical procedures were performed (major: $n=27$; minor $n=30$ ). For 32 patients, representing the majority of patients (59.4\%), had type 3 VWD.

In this study, the efficacy of Wilate ${ }^{\circledR}$ was rated by the investigator as excellent or good in $96 \%$ of procedures. Tolerability was rated as very good or good in $100 \%$ of major surgeries, without any risk of accumulation of FVIII or thrombotic complications. In our case, we notice a parallel evolution of VWF: RCo and FVIII: $C$ time curves after the administration of multiple doses of Wilate ${ }^{\circledR}$. This result was also reported in the study of Windyga, et al. [6] and indicates that there was no accumulation of FVIII with Wilate ${ }^{\circledR}$. This is an important observation, because elevated plasmaFVIII levels have been reported to be associated with an increased risk of venous thrombosis and the risk is heightened in patients undergoing surgery $[17,18]$. No thromboembolic events were recorded in our patient or in a study of on-demand and prophylactic use of Wilate ${ }^{\circledR}[14]$.

\section{Conclusion}

The good control of hemostasis and close perioperative follow-up under VWF/FVIII concentrate are important to perform a major surgical procedure, safely, in vWD type 3 patients. To the best of our knowledge, this is the first case reported of a surgical procedureunder VWF/FVIII concentrate Wilate ${ }^{\circledR}$, performed in a patient with VWD type 3 in Morocco. This case provides encouragement for the performance of major surgical procedures with the support of VWF/FVIII concentrate even in severe cases of Willebrand diseases exposing the patient to a high risk of postoperative bleeding.

\section{Conflicts of interest}

There is no conflict of interest.

\section{References}

1. Calmette L, Clauser S (2018) La maladie de willebrand. Rev Med Interne.

2. Sadler JE, Budde U, Eikenboom JC, et al. (2006) Update-t-on the pathophysiology and classification of von willebrand disease: $A$ report of the subcommittee on von willebrand factor. J Thromb Haemost 4: 2103-2014.

3. Fressinaud E (2014) Facteur willebrand et maladie de willebrand: Pré-requis au diagnostic. Hematologie 20: 6-13. 
4. Zulfikara B, Koca B, Akb G, et al. (2016) Surgery in patients with von willebrand disease. Blood Coagul Fibrinolysis 27: 812-816.

5. Mannucci PM, Kyrle PA, Schulman S et al. (2013) Prophylactic efficacy and pharmocokinetically guided dosing of a von willebrand factor/factor VIII concentrate in adults and children with von willebrand's disease undergoing elective surgery: A pooled and comparative analysis of data from USA and European Union clinical trials. Blood Transfus 11: 533-540.

6. Windyga J, Von Depka-Prondzinski M, European Wilate ${ }^{\circledR}$ Study Group (2011) Efficacy and safety of a new generation von Willebrand factor/factor VIII concentrate (Wilate ${ }^{\circledR}$ ) in the management of perioperative haemostasis in von Willebrand disease patients undergoing surgery. Thromb Haemost 105: 1072-1079.

7. Stadler M, Gruber G, Kannicht C, et al. (2006) Characterisation of a novel high-purity, double virus inactivated von willebrand factor and factor VIII concentrate (Wilate). Biologicals 34: 281-288.

8. Haute Autorité de Santé (2018) Protocole national de diagnostic et de soins (PNDS) maladie de willebrand. Centre de Référence de la Maladie de Willebrand.

9. Laffan MA, Lester W, O Donnell JS, et al. (2014) The diagnosis and management of von willebrand disease: A United Kingdom haemophilia centre doctors organization guideline approved by the british committee for standards in haematology. Br J Haematol 167: 453-465.

10. Heijdra JM, Cnossen MH, Leebeek FWG (2017) Current and emerging options for the management of inherited von willebrand disease. Drugs 77: 1531-1547.
11. Nichols WL, Hultin MB, James AH, et al. (2008) Von willebrand disease (VWD): Evidence-based diagnosis and management guidelines, the National Heart, Lung, and Blood Institute (NHLBI) Expert Panel report (USA). Haemoph Off J World Fed Hemoph 14: 171-232.

12. Mannucci PM, Franchini M, Castaman G, et al. (2009) Evidence-based recommendations on the 73 treatment of von willebrand disease in Italy. Blood Transfus Trasfus Sangue 7: 117126.

13. De Wee EM, Leebeek FWG, Eikenboom JCJ (2011) Diagnosis and management of von willebrand disease in The Netherlands. Semin Thromb Hemost 37: 480-487.

14. Berntorp E, windyga J, european wilate study group (2009) Treatment and prevention of acute bleedings in von willebrand disease-efficacy and safety of wilate, a new generation von willebrand factor/factor VIII concentrate. Haemophilia 15: 122-130.

15. Mannucci PM (2004) Treatment of von willebrand's disease. N Engl J Med 351: 683-694.

16. Auerswald G, Bade A, Haubold K, et al. (2013) No inhibitor development after continuous infusion of factor concentrates in subjects with bleeding disorders undergoing surgery: A prospective study. Haemophilia 19: 438-444.

17. Koster T, Blann AD, Briet E, et al. (1995) Role of clotting factor VIII in effect of von willebrand factor on occurrence of deep-vein thrombosis. Lancet 345: 152-155.

18. Bank I, Libourel EJ, Middeldorp S, et al. (2005) Elevated levels of FVIII: $\mathrm{C}$ within families are associated with an increased risk for venous and arterial thrombosis. J Thromb Haemost 3: 79-84.

DOI: $10.36959 / 831 / 381$

Copyright: (C) 2020 Bencharef $\mathrm{H}$, et al. This is an open-access article distributed under the terms of the Creative Commons Attribution License, which permits unrestricted use, distribution, and reproduction in any medium, provided the original author and source are credited. 